\title{
Detection of some virulence factors of Salmonella typhi isolated from patients' blood by PCR and Phylogenetic tree
}

\author{
Najlaa Abdullah D. AL-Oqaili \\ College of Biotechnology, University of Al-Qadisiyah, Iraq \\ najlaa67890@gmail.com
}

\begin{abstract}
Typhoid fever is brought about by Salmonella enterice serovar typhi, which is a significant general medical issue in many developing nations. The severity the pathogenesis depends on Salmonella's possession of cytolethal distending toxin (CDT) and virulence factors such as fimbriae adhesions, which are important in the adherence, invasion and the development of typhoid fever, was as diagnosed serologically as well as diagnosis of Salmonella typhi causing these fever based on phenotypic and cultural characteristics. Therefore, the coding genes of CdtB protein and fimbriae were detected in molecular methods by PCR technique using special primers. while, the fim gene was $84.21 \%$ and $C d t B$ gene was $100 \%$. DNA sequencing was performed and this confirms the isolation obtained in our study. In addition, the phylogenetic tree was analyzed and registered at the gene bank site, where the sequence identity rate fim gene $99.26 \%$, while sequence identity rate for $C d t B$ gene was $99.31 \%$.
\end{abstract}

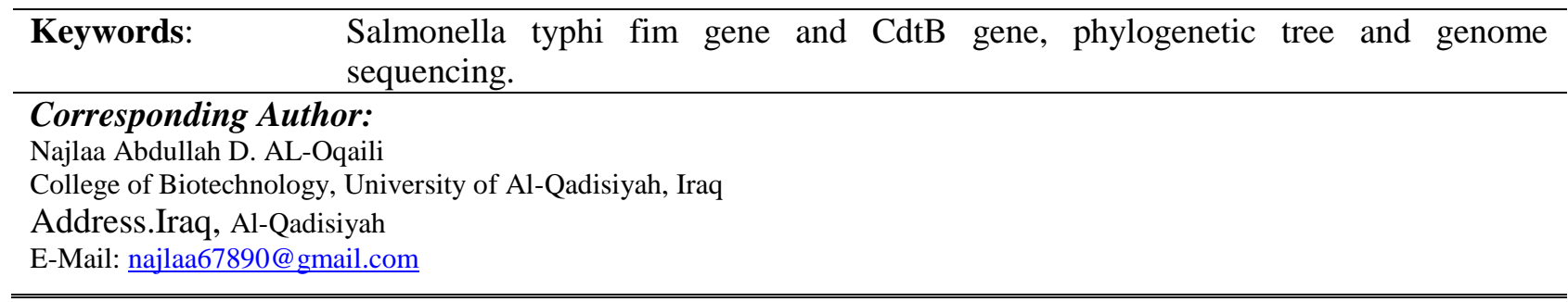

\section{Introduction}

Salmonella species enter their human by the intestinal area and irritated the mucous membrane of intestinal tract [1], the reason for typhoid fever, a fundamental, hazardous infection of people [2-6]. S.typhi is etiologic specialist, can be transmitted through tainted nourishment and water by means of the oral-fecal course. Yearly, more than 21 million cases and almost 200, 000 passing's are accounted for around the world [7]. The internal compositions of S.typhi, such as the fatty polysaccharides, pili and surface are influence the invasion factors of the bacteria [8]. The different kinds bacterial utilize comparative contamination methodologies because of the securing of assorted pathogenicity islands, a locale should convey qualities encoding at least one invasion factors for example adhesions, enzymes, and attacks, pathogenicity islands are found on the pathogen genetic material or on a plasmid and convey functional genes for DNA recombine, for example, integrase, transposase, or part of an insert element [9]. Multiple survival strategies allow S.typhi Caused typhoid fever disease outbreaks in different developed nations [10].

The Fimbriae are proteinaceous extracellular structures chiefly associated with attachment, an essential beginning advance for migration and passage into have cells, fimbriae have additionally been appeared by way of macrophages, intestinal ingenuity, biofilm development and bacteria collection in other Salmonella serovars [11-14]. The imperfection in swimming might be expected through abatement in development level or By over-expression of fimbriae fim, S.typhi pathogenesis, can be a significant role and other fimbriae and invasion factors, such as flagella, LPS, it can be controlled [15]. Bacteria S.typhi also contains of cytolethal distending toxin, the (CDT) consists of three subunit [16]. CdtA and CdtC structure a heterologous B subunit this is vitality for the conveyance of $\mathrm{CdtB}$, the dynamic or A subunit [17].

The structure of act for toxin is sensibly surely known, on conveyance to have cells by CdtA and CdtC, the dynamic subunit $\mathrm{CdtB}$ is distributed to the center where it causes genome harm $[18,19]$. The CDT is coded through operon made out of the cdtA, cdtB, and cdtC genes [20,21]. The ongoing assurance of the whole nucleotide succession of the genomes of double single strains of Salmonella enterica serovar Typhi (S. typhi), 
it has caused typhoid fever [22,23]. The CdtB toxin is a recently renowned invasion factors of Salmonella enterica subsp. serovar Typhi [24], quite represent wide range of other enterobacteriaceae pathogens, host cellular inebriated by CdtB show a DNA damage response (DDR) characterized by irreparable cells harm, through tireless DDR prompting cellular death by apoptosis [25], given the meaning of the role of invasion factors and toxins in cause of typhoid fever disease, that main focus of this research was to isolate and diagnose S.typhi strains from supposed blood, investigate the existence of fim gene and coding gene for cdtB protein, as well as examine the DNA sequence for confirmatory diagnosis and phylogenetic tree analysis.

\section{Materials \& Methods}

\section{Clinical specimens and identification of bacteria}

During the period from May 2018 to February 2019, 86 blood specimens were collected at General Teaching Hospital in AL-Diwaniya city and suspected outpatient's patients for typhoid fever. The specimens were transplanted on blood also, macConkey agar that brooded at a temperature of $37 \mathrm{C}^{\circ}$ for $24-48$ hours, every single bacterial state were initially diagnosed on phenotypic, cultural characteristics and biochemically [26,27], as well as the discovery of the typhoid antibodies in blood specimen by widal examination [28].

\section{Molecular Identification}

DNA extraction from S.typhi isolates by DNA purification kit (Geneaid, USA). DNA preparation were then analyzed via electrophoresis thereof $1.5 \%$ agarose gel. PCR be used to amplify the entire sequences of the genes studied in this research. The specific primers (Bioneer company, Korea) utilized for the expansion to these genes were shown in (table 1).

The PCR mixtures contained: Top DNA polymerase 1U, dNTP (dATP, dCTP, dGTP, dTTP) each:250mM, Tris-HCL (pH 9.0) $10 \mathrm{mM}, \mathrm{KCL} 30 \mathrm{mM}, \mathrm{MgCL}_{2} 1.5 \mathrm{mM}$. and polymerase chain reaction (PCR) thermocycling conditions were shown in (table 2).

Table 1 . The primer sequences of virulence gene \& toxin in this study.

\begin{tabular}{cccc}
\hline Primers & & Sequence & Amplicon \\
\hline 16SrRNA & $\mathrm{F}$ & CCTGGACAAAGACTGACGCT & $523 \mathrm{bp}$ \\
& $\mathrm{R}$ & CGCTTCTCTTTGTATGCGCC & \\
S.typhi & & GTGAGCGGCGGTACTATTCA & $451 \mathrm{bp}$ \\
fimA & $\mathrm{F}$ & TAAAGGTGGCGTCGGCATTA & \\
& $\mathrm{R}$ & TAAGTGGTACTGCCGGTGTG & $508 \mathrm{bp}$ \\
CdtB & $\mathrm{F}$ & GTAGGTGCGAGTACGGCTAC & \\
& $\mathrm{R}$ &
\end{tabular}

Table 2. PCR thermocycling conditions

\begin{tabular}{cccc}
\hline PCR steps & Temperature $\left({ }^{\mathbf{0}} \mathbf{C}\right)$ & Time Period & return \\
\hline Initial Denaturation & 95 & $5 \mathrm{~min}$. & 1 \\
Denaturation & 95 & $30 \mathrm{sec}$. & \\
Annealing & 58 & $30 \mathrm{sec}$. & \\
Extension & 72 & $1 \mathrm{~min}$. & 30 cycle \\
& & & \\
Final extension & 72 & $5 \mathrm{~min}$. & 1 \\
Hold & 4 & forever & - \\
\hline
\end{tabular}

\section{DNA Sequencing and Analysis}


The isolates were sent from the reaction products of $16 S$ rRNA gene to confirm the diagnosis of S.typhi through the analysis the phylogenetic tree, the results were compared and analyzed using NCBI BIAST.

\section{Results}

The results of the current study for widal test showed a positive result for 44 patients out of 86 total blood specimens of clinically suspected patients with typhoid fever, also showed 26 (59\%) isolation of S.typhi depending on phenotypic and culture characteristics. While the results of the current study PCR technique showed 19 isolates of S.typhi possessed the 16S rRNA gene (Fig.1).

The results of our study some virulence factors and toxins, it was found that most of isolates carried the fim gene was at rate $(84.21 \%, 16 / 19)$ (Fig.2) and $C d t B$ gene was $(100 \%, 19 / 19)($ Fig.3).

DNA Sequencer:

The results of the analysis showed the gene sequence of $16 S$ rRNA between local salmonella enterica subsp. enterica serovar typhi isolates and (NCBI-Gene bank) BLAST salmonella enterica subsp. enterica serovar typhi isolates, the sequence identity rate was $(99.26 \%)$ for fim gene (Table 3), either sequence identity rate for $C d t B$ gene was $(99.31 \%$ ) in (Table 4). Our study also showed the phylogenetic tree analysis of fim gene and compared it with other isolates deposited in the (NCBI-Gene bank) as shown in (Fig. 4,5), while the result of the analysis of the other $C d t B$ gene is shown in (Fig. 6,7).

Table 3. Local and NCBI BLAST Salmonella enterica subsp. homology sequence identity Enterica serovar typhi isolates

\begin{tabular}{ccccc} 
Local isolate & $\begin{array}{c}\text { Genbank } \\
\text { accession } \\
\text { number }\end{array}$ & Identical isolate & $\begin{array}{c}\text { Homology sequence identity } \\
\text { Genbank } \\
\text { accession } \\
\text { number }\end{array}$ & Identity \\
\hline $\begin{array}{c}\text { Salmonella enterica } \\
\text { subsp. } \text { enterica } \\
\text { serovar Typhi isolate }\end{array}$ & MN839770 & $\begin{array}{c}\text { Salmonella enterica } \\
\text { subsp. } \\
\text { enterica serovar Typhi } \\
\text { strain 311189-291186 }\end{array}$ & CP029894.1 & $99.26 \%$ \\
& & & & \\
\hline
\end{tabular}

Table 4. Local and NCBI BLAST Salmonella enterica subsp. homology sequence identity Enterica serovar typhi isolates

\begin{tabular}{ccccc}
\hline Local isolate & $\begin{array}{c}\text { Genbank } \\
\text { accession } \\
\text { number }\end{array}$ & Identical isolate & $\begin{array}{c}\text { Homology sequence identity } \\
\text { Genbank } \\
\text { accession } \\
\text { number }\end{array}$ & Identity \\
\hline $\begin{array}{c}\text { Salmonella enterica } \\
\text { subsp. enterica serovar } \\
\text { Typhi isolate }\end{array}$ & MN839769 & $\begin{array}{c}\text { Salmonella } \\
\text { enterica } \text { subsp. } \\
\text { enterica } \text { strain FSL } \\
\text { M8-0480 }\end{array}$ & KX810912.1 & $99.31 \%$ \\
\hline
\end{tabular}

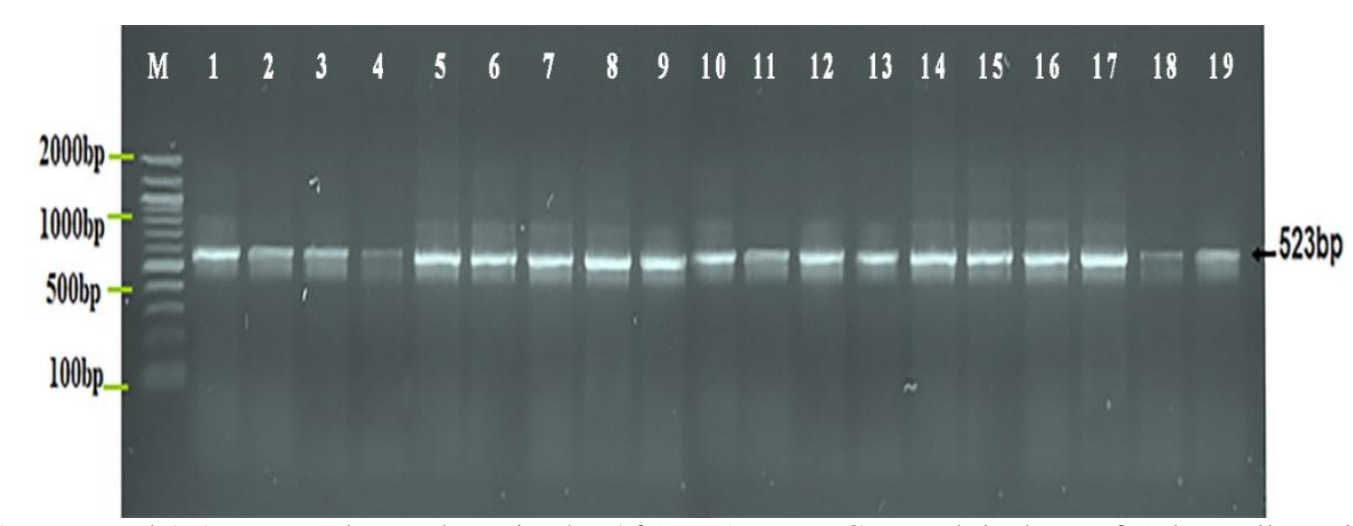

Figure 1. Agarose gel 1.5 percent electrophoresis, the 16SrRNA gene PCR result isolates of Salmonella typhi. Where M: Marker (100-2000bp), lane (1-19) positive PCR (523bp) PCR producer size amplification. 


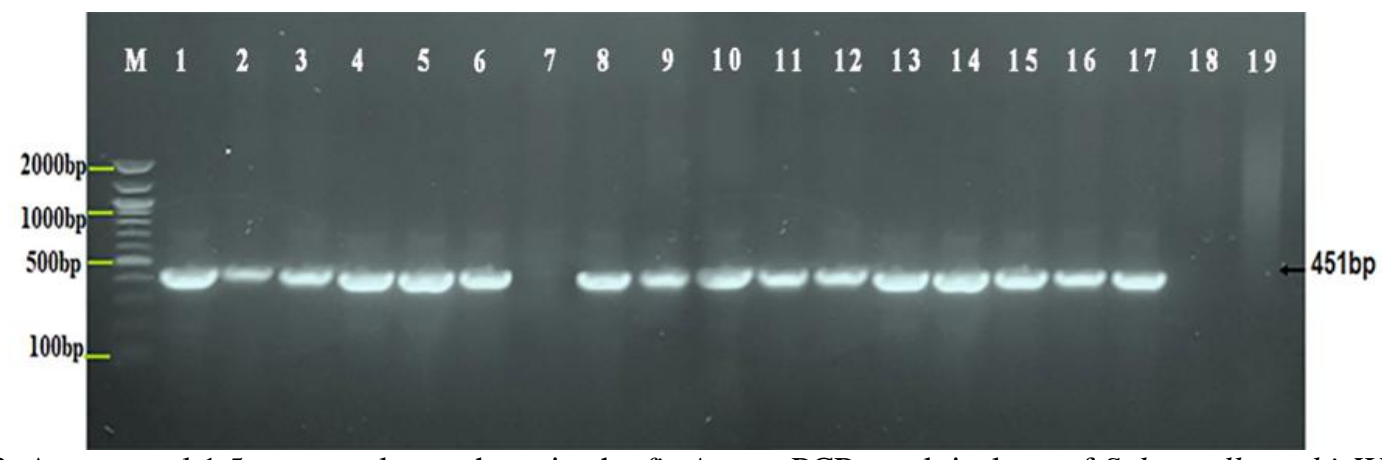

Figure 2. Agarose gel 1.5 percent electrophoresis, the fimA gene PCR result isolates of Salmonella typhi. Where M: Marker (100-2000bp), lane (1-6) and (8-17) positive PCR (451bp) PCR producer size amplification

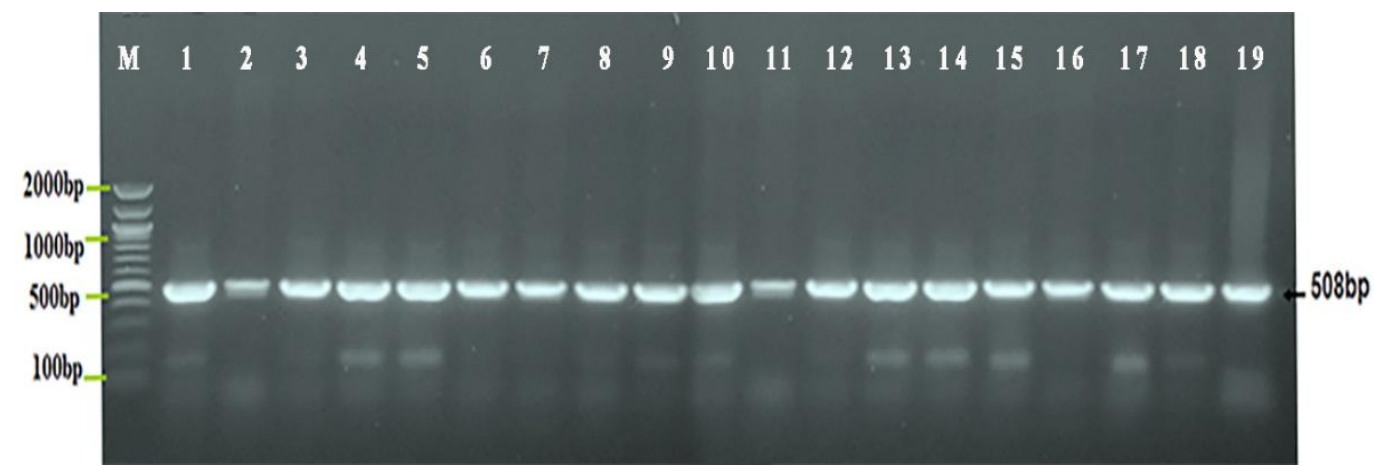

Figure 3. Agarose gel 1.5 percent electrophoresis, the $C d t B$ gene PCR result isolates of Salmonella typhi. Where M: Marker (100-2000bp), lane (1-19) positive PCR (508bp) PCR producer size amplification

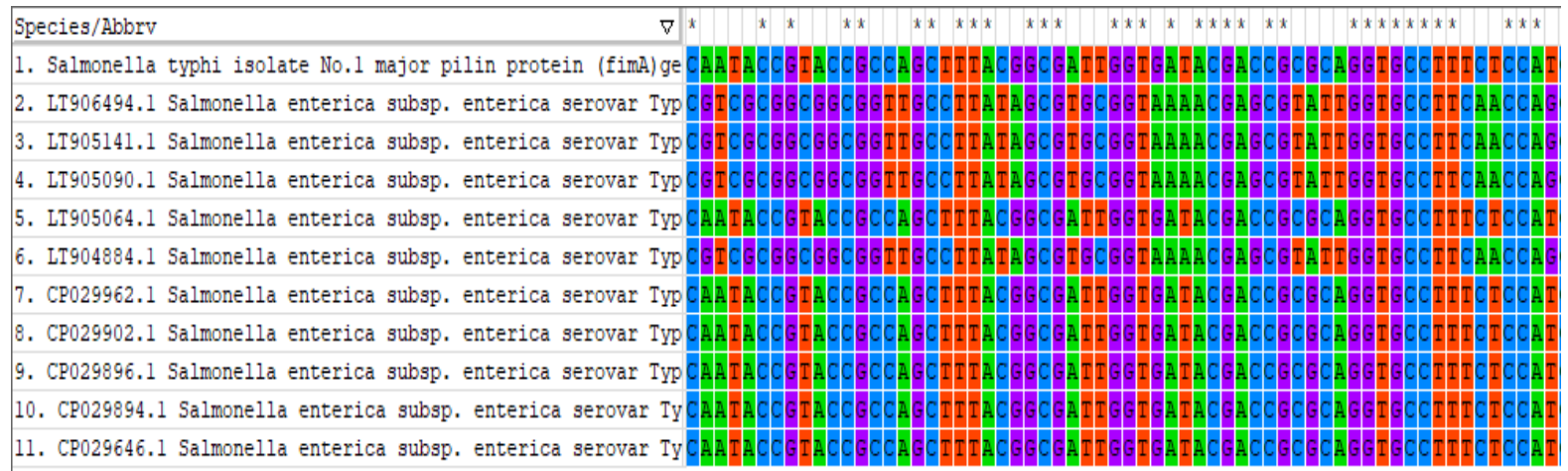

Figure 4. Multiple sequence alignment analysis of major pilin protein (fimA) gene partial sequence between local isolation and different isolates in the NCBI-Genbank for Salmonella enterica subsp. enterica serovar Typhi according to

ClustalW alignment test
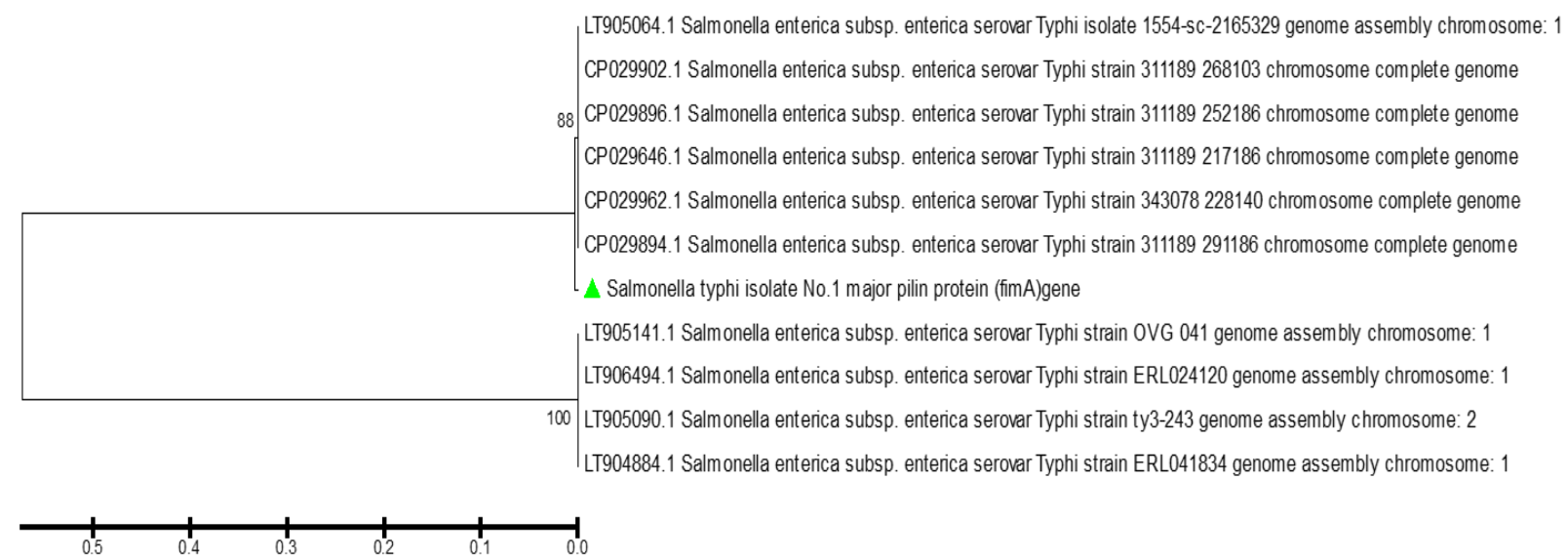

Figure 5. Phylogenetic tree analysis based on the partial sequence of major pilin protein (fimA)gene in local Salmonella enterica subsp. enterica serovar Typhi isolates that use for genetic analysis 


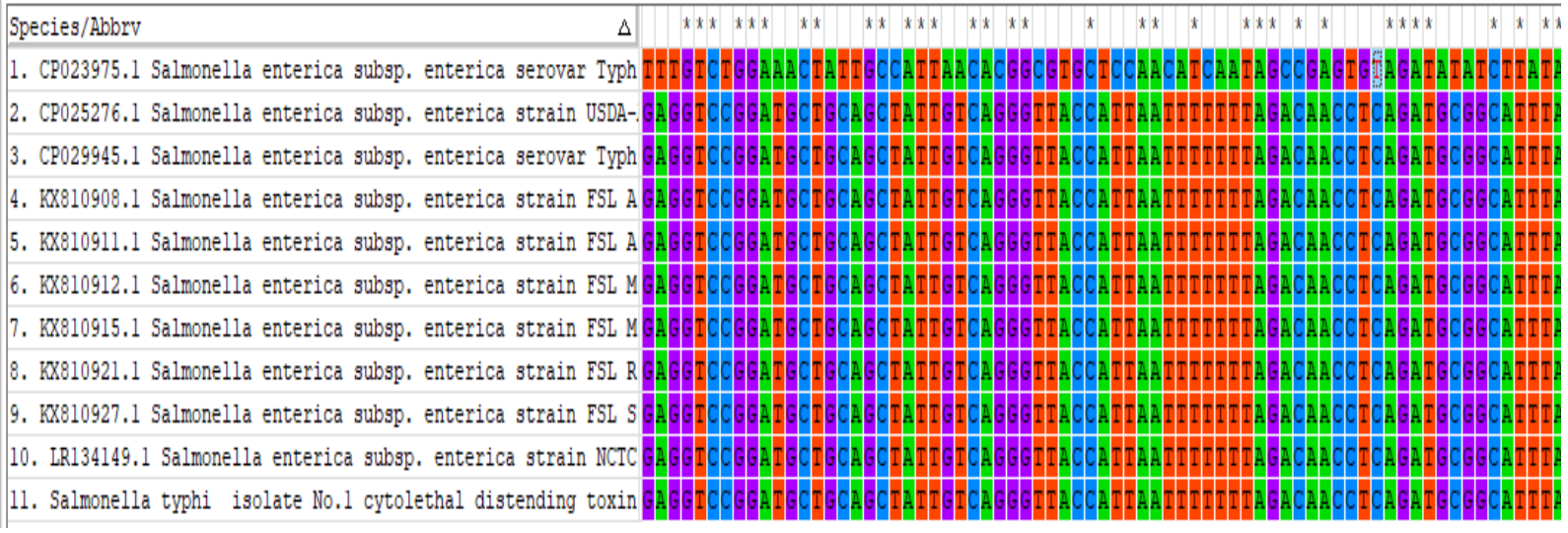

Figure 6. Multiple sequence alignment analysis of cytolethal distending toxin B (CdtB) gene partial sequence between local isolation and different isolates in the NCBI-Genbank for Salmonella enterica subsp. enterica serovar Typhi according to ClustalW alignment test

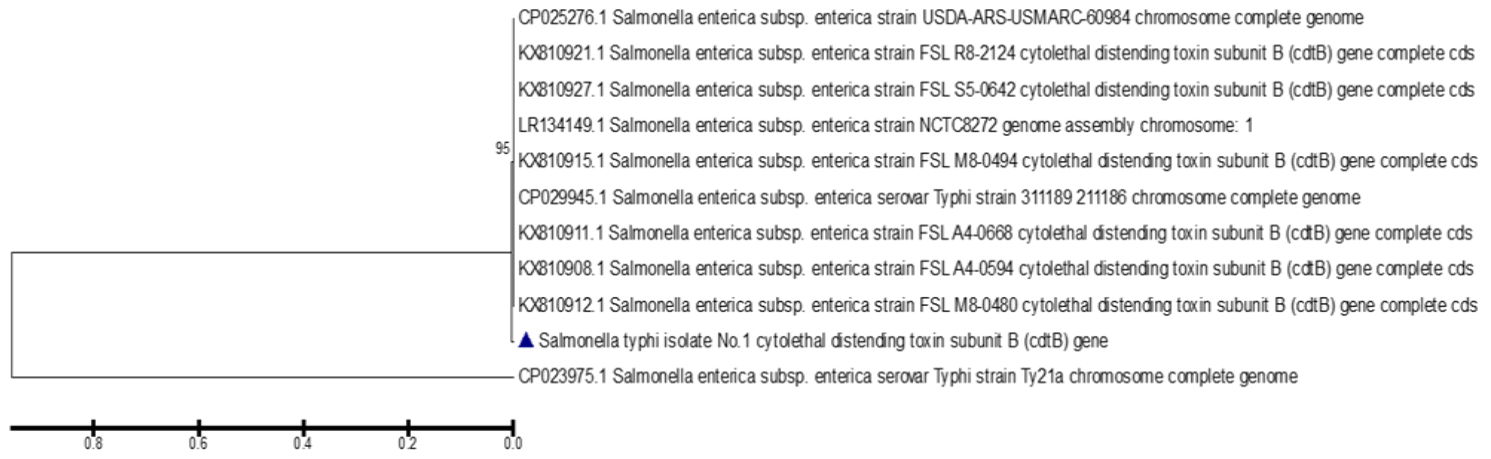

Figure 7. Phylogenetic tree analysis based on the partial sequence of cytolethal distending toxin B $(C d t B)$ gene in local Salmonella enterica subsp. enterica serovar Typhi isolates that use for genetic analysis

\section{Discussion}

Typhoid fever causes estimated (5-30\%) deaths in people in developing countries, the World Health Organization (WHO) estimates that between 16 and 17 million cases happen each year approximately 600,000 death-rate vary from district to district, but may be reach high as 5-7\% although the usage of suitable antibiotics drugs [29]. Typhoid fever is also a major disease among young children and young adults in Nigeria, due to lack adequate facilities and misuse antibiotics [30,31]. These studies are consistent with our current study, showing that all S.typhi isolates were carried of fimA gene about $84.21 \%$ and $C d t B$ genes about $100 \%$ as shown in (Fig.2 and Fig.3) respectively that enable them to developed symptoms of typhoid fever. Karine et al.[32] show athat all S.typhi fimbriae were better expressed in minimal broth that had six genes from within 12 chaperone-usher fimbriae that display extracellular structure by electron microscopy and show that when overexpressed only fimbriae had an effect on motility [32]. Fimbriae are tiny hair-like protein compositions on the cell surface that play about a dangerous role in the invasion by letting bacteria to happen interact with specific receptors of host cells [33].

As for the multiple sequence alignment analysis of major pilin protein fimA in our current study were showed the nucleotide similarity and substitution mutation in fimA gene nucleotide sequences as in (Fig. 4), also in our research, phylogenetic tree analysis based on the partial sequence of the main pilin protein reveals that the evolutionary distances are determined using the total composite likelihood model of the UPGMA tree (MEGA 6.0 version) as shown in (Fig. 5). In addition, there is a similarity in the sequence of nitrogenous bases of the fimA gene between the local and global isolation deposited in the (NCBI-Gene bank) where the proportion of high conformity of this gene at a rate of (99.26\%) as shown in (table 3). Where the study proved Yap et al. [34], MLST data revealed that there was no guide of bias in the spatial and time distribution of STs, 
suggesting that human migration rates across continents were very high to diffusion equal genotypes through people populations.

Human pathogens causing Cdt contain: an oral pathogen, a genital pathogen responsible for sexually transmitted cancroid, stomach pathogens, and cancer pathogens [35-37]. CDT consists of three proteins, CdtA, CdtB, and CdtC, CdtB being enzyme active or A secondary unit, having DNase I-very active, while CdtA and CdtC serve as heterogeneous B secondary units mediate the transmission of CdtB to host cells [38]. The $C d t B$ gene has been detected in isolates from the blood of patients who have typhoid fever in our current study at a high rate of $100 \%$, our study also found that multiple sequence alignment analysis of cytolethal distending toxin B were showed the nucleotide similarity and substitution mutation in $c d t B$ gene nucleotide sequences as in (Fig.6), even analysis of the phylogenetic tree based on partial sequences of CdtB toxin as shown in (Fig.7). In addition, there is a similarity between identical and local isolation of the sequence of nitrogen bases of the $C d t B$ gene at a rate of $99.31 \%$ as shown in (table 4).

That our study corresponds with Rivera et al. [38] where he showed that CdtB-islet coding the cytolethal distending toxin B is an invasion factor that not only one currently present in Salmonella enterica subsp. Enterica serovar typhi (Salmonella typhi) and hundreds of Gram negative bacterial as well as non-typhoidal serovars Salmonella (NTS).

There is a comparison in previous studies with all another bacteria that express Cdt, Salmonella enterica serotype Typhi (S.typhi) limited genes that code CdtA and CdtC [39-41].

S.typhi genome sequence has gave a wide look into its evolutionary history and phylogenetic analysis indicates this bacterium is powerfully monomorphic and may by entered recently the human enumeration [4244]. The S.typhi chromosome has predicted a high than number of pseudogenes, an indicator that human-host adaptation cycle leads to a reduction in its genome [45,46]. These observations suggest that $C d t B$ plays a role as an important Salmonella spp. of virulence attribute [47].

\section{Conclusion}

In conclusion, the current study showed that typhoid fever caused by S.typhi, which was isolated from infected patients; most of them were carriers of virulence factors that increase the pathogenicity of the fever, as well as the presence of typhoid toxin. This plays an active role in the severity of the bacteria's disease, which is the human carrier in his blood lead to damage the body cells by the coding gene of toxin and fimbriae proteins. The rate of fimA gene and $c d t B$ gene is high, which has an impact on the phenotype and genetic pattern of bacteria.

\section{References}

[1] M. A. Clark, M. A. Jepson, N. L. Simmons, and B. H. Hirst. Preferential interaction of Salmonella typhimurium with mouse Peyer's patch M cells. Res. Microbiol. 145, 543-552, 1994.

[2] C.M. Parry, T. T. Hien , G. Dougan, N. J. White, J. J. Farrar. Typhoid fever. N Eng.l J. Med. 347(22):1770-1782, 2002.

[3] J. A. Crump, E. D. Mintz . Global trends in typhoid and paratyphoid Fever. Clin. Infect. Dis. 50(2):241$246,2010$.

[4] M. Raffatellu, R. P. Wilson, S. E. Winter, A. J. Bäumler. Clinical pathogenesis of typhoid fever. J. Infect. Dev. Ctries 2(4):260-266, 2008.

[5] J. Wain , R. S. Hendriksen, M. L. Mikoleit , K. H. Keddy, R. L. Ochiai. Typhoid fever. Lancet 385(9973):1136-1145,2015.

[6] G. Dougan , S. Baker. Salmonella enterica serovar Typhi and the pathogenesis of typhoid fever. Annu. Rev. Microbiol. 68:317-336,2014.

[7] J. A. Crump, and E. D. Mintz. Global trends in typhoid and paratyphoid fever. Clin. Infect.Dis. 50, 241246, 2010. 
[8] W. Robert Crawford. Very long O-antigen chains enhance fitness during Salmonella-induced colitis by increasing bile resistance. Department of Medical Microbiology and Immunology, School of Medicine, University of California at Davis, California, USAPLoS Pathog. 8: e1002918, 2012.

[9] T. M. Wassenaar , and W. Gaastra . Bacterial virulence: can we draw the line. FEMS Microbiol. Lett, 201:1-7, 2001.

[10] J. Wain, and S. Hosoglu. the laboratory diagnosis of enteric fever, Journal of Infectious Developing Countries, vol. 2, no. 6, pp. 421-425, 2008.

[11] R. A. Edwards, D. M. Schifferli , and S. R. Maloy. A role for Salmonella fimbriae in intraperitoneal infections. Proc. Natl. Acad. Sci. U.S.A. 97,1258-1262, 2000.

[12] I.S. Tsui , C. M. Yip, J. Hackett, and C. Morris . The type IVB pili of Salmonella enterica serovar Typhi bind to the cystic fibrosis transmembrane conductance regulator. Infect. Immun. 71, 6049-6050, 2003.

[13] E. H. Weening, J. D. Barker, M .C. Laarakker, A. D. Humphries, R. M. Tsolis, and A. J. Bäumler, The Salmonella enterica serotype Typhimurium lpf, bcf, stb, stc, std, and sth fimbrial operons are required for intestinal persistencein mice. Infect. Immun. 73, 3358-3366,2005.

[14] N. A. Ledeboer, J.G. Frye, M. McClelland, and B. D. Jones. Salmonella enterica serovar Typhimurium requires the Lpf, Pef, and Tafi fimbriae for biofilm formation on HEp-2 tissue culture cells and chicken intestinal epithelium. Infect. Immun. 74, 3156-3169, 2006.

[15] K. Dufresne, J. Saulnier-Bellemare, and F. Daigle . Functional Analysis of the Chaperone-Usher Fimbrial Gene Clusters of Salmonella enterica serovar Typhi. Front Cell Infect. Microbiol. 8:26, 2018.

[16] M. Lara-Tejero, and J. F. Galan. Cytolethal distending toxin: limited damage as a strategy to modulate cellular functions. 10(3): 147-152,2002.

[17] M. Lara-Tejero, and J.F. Galan. immunity, $C d t A, C d t B$, and $C d t C$ form a tripartite complex that is required for cytolethal distending toxin activity. 69(7):4358-4365, 2001.

[18] M. Lara-Tejero, M. and J. F. Galan. A bacterial toxin that controls cell cycle progression as a deoxyribonuclease I-like protein. 290(5490): 354-357, 2000.

[19] C. A. Elwell, and L. A. Dreyfus. DNase I homologous residues in CdtB are critical for cytolethal distending toxin-mediated cell cycle arrest. 37(4):952-963, 2000.

[20] D. A. Scott, and J. Kaper . Immunity, Cloning and sequencing of the genes encoding Escherichia coli cytolethal distending toxin. 62(1): 244-251, 1994.

[21] C. L. Pickett, et al. Cloning, sequencing, and expression of the Escherichia coli cytolethal distending toxin genes. 62(3):1046-1051, 1994.

[22] J. Parkhill, et al. Complete genome sequence of a multiple drug resistant Salmonella enterica serovar Typhi CT18.413(6858):848, 2001.

[23] W. Deng, et al.Comparative genomics of Salmonella enterica serovar Typhi strains Ty2 and CT18. 185(7):2330-2337,2003.

[24] E. Haghjoo, J. E. Galn. Salmonella Typhi encodes a functional cytolethal distending toxin that is delivered into host cells by a bacterial internalization pathway. Proc. Natl. Acad. Sci. USA 101:46144619, 2004. 
[25] R. N. Jinadasa , S. E. Bloom, R. S. Weiss, G. E. Duhamel. Cytolethal distending toxin: a conserved bacterial genotoxin that blocks cell cycle progression, leading to apoptosis of a broad range of mammalian cell lineages. Microbiology 157:1851-1875, 2011.

[26] J. F. Macfaddin . Biochemical Tests for Identification of Medical Bacteria. 3rd ed. Lippincott Williams and Wilkins, USA, 2000.

[27] J.C. Collee, A. G. Fraser, B. P. Marmiam, and S. A. Simmon . Mackie and McCartney; Practical Medical Microbiology. 24th ed. The Churchill Livingstone. Inc. USA, 1996.

[28] S. K. Saha, M. Ruhulamin, M. Hanif, M. Islam. and A. Khan. Interpretation of the Widal test in the diagnosis of typhoid fever in Bangladeshi children. Ann. Trop.Paediatr. 16, 75-78 1,2, 1996.

[29] C. A. Scherer, and S. I. Miller. Molecular pathogenesis of Salmonellae In Principles of Bacterial Pathogenesis Principles of Bacterial Pathogenesis, Groisman, E. A. (Ed). Academic Press, United States of America; pp:265-316, 2001.

[30] H. A. Talabi, H. A. Medical aspects of typhoid fever in Nigeria. Nig. Post grad. Med. J.1:51-56, 1994.

[31] K. O. Akinyemi, S. I. Smith, A. O. Oyefolu, A. O. Coker. Multidrug resistance in Salmonella enterica serovar Typhi isolated from patients with typhoid fever complications in Lagos, Nigeria. Public Health 119:321-327, 2005.

[32] K. J. Dufresne and F. Daigle. Functional Analysis of the Chaperone-Usher Fimbrial Gene Clusters of Salmonella enterica serovar Typhi. Front Cell Infect. Microbiol., 8:26, 2018.

[33] K. P. Yap, et al. Global MLST of Salmonella Typhi Revisited in Post-Genomic Era: Genetic Conservation, Population Structure, and Comparative Genomics of Rare Sequence Types. Front Microbiol.,7: 270, 2016.

[34] B.J. Shenker, T. L. McKay, S. Datar, M. Miller, R. Chowhan, and D. R. Demuth. Actinobacillus actinomycetemcomitans immunosuppressive protein is a member of the family of cytolethal distending toxins capable of causing a G2 arrest in human T cells. J. Immun. 162,4773-4780, 1999.

[35] Z. Ge , Y. Feng, M. T. Whary, P. R. Nambiar, S. Xu ,et al.Cytolethal distending toxin is essential for Helicobacter hepaticus colonization in outbred Swiss Webster mice. Cell. microbial. 73,201-206, 2005.

[36] J. M. DiRienzo . Breaking the gingival epithelia barrier: role of the Aggregatibacter actinomycetemcomitans cytolethal distending toxin in oral infectious disease. Cells 3:476-499, 2014.

[37] E. Haghjoo, and J. E. Galan . Salmonella typhi encodes a functional cytolethal distending toxin that is delivered into host cells by a bacterial-internalization pathway. Proc.Natl. Acad. Sci. USA. 101(13): 4614-9, 2006.

[38] F. Chantal, P. F. Sebastien, P. Katherine , H. Sebastien, M. D. Charles, D. France. Contribution of the stg fimbrial operon of Salmonella enterica serovar Typhi during interaction with human cell. Infect. Immun. 75: 5264-5271, 2007.

[39] E. Haghjoo, and J. E. Galán. Salmonella typhi encode a functional cytolethal distending toxin that is delivered into host cells by a bacterial- internalization pathway. Proc. Natl. Acad. Sci. U.S.A. 101:4614 4619, 2004.

[40] J. Suez, S. Porwollik, A. Dagan, A. Marzel, Y. Schorr, P. Desai, et al. Virulence gene profiling and pathogenicity characterization of non-typhoidal Salmonella accounted for invasive disease in humans. PLoS ONE 8: e58449,2013. 
[41] R. Figueiredo, R. Card, C. Nunes , M. AbuOun, M. C. Bagnall, J. Nunez, et al. Virulence characterization of Salmonella enterica by a New microarray: detection and evaluation of the cytolethal distending toxin gene activity in the unusual host S. Typhimurium. PLoS ONE 10: e0135010, 2015.

[42] J. Parkhill, et al. Complete genome sequence of a multiple drug resistant Salmonella enterica serovar Typhi CT18. Nature 413(6858):848-852, 2001.

[43] S. Baker, G. Dougan. The genome of Salmonella enterica serovar Typhi. Clin. Infect. Dis. 45(1): S29S33, 2007.

[44] M. Achtman. Evolution, population structure, and phylogeography of genetically monomorphic bacterial pathogens. Annu. Rev. Microbiol. 62:53-70,2008.

[45] M. E. Ohl, S. L. Miller. Salmonella: A model for bacterial pathogenesis. Annu. Rev. Med. 52:259-274, 2001.

[46] G. A. Grassl, and B. B. Finlay. Pathogenesis of enteric Salmonella infections. Curr. Opin Gastroenterol. 24(1):22-26, 2008.

[47] M. D. Scuron, et al. The Cytolethal Distending Toxin Contributes to Microbial Virulence and Disease Pathogenesis by Acting as a Tri-Perditious Toxin. Front Cell Infect. Microbiol, 6:168, 2016. 